\title{
My escape from the lab: scientific publishing - 1st year Grad Students \& Undergrads
}

\author{
Matteo Cavalleri ${ }^{1}$
}

${ }^{1}$ Affiliation not available

February 18, 2021

\begin{abstract}
Across the world and across disciplines, numbers reveal that the term "alt-ac" - referring to positions within higher education and research alternative to the professoriate - is a misnomer. Permanent academic jobs are, in fact, the "alt-ac". In this talk, I'll share my (happy) experience going from a computational chemistry lab to my current career on the "other side" of scientific publishing, and explore roles for STEM Ph.D.s in the publishing industry. Talk especially tailored for 1st Year Grad Students \& Undergrads.
\end{abstract}

Rich media available at https://speakerdeck.com/teowaits/my-escape-from-the-lab-scientificpublishing-1st-year-grad-students-and-undergrads

Journal Editor: A day in the life

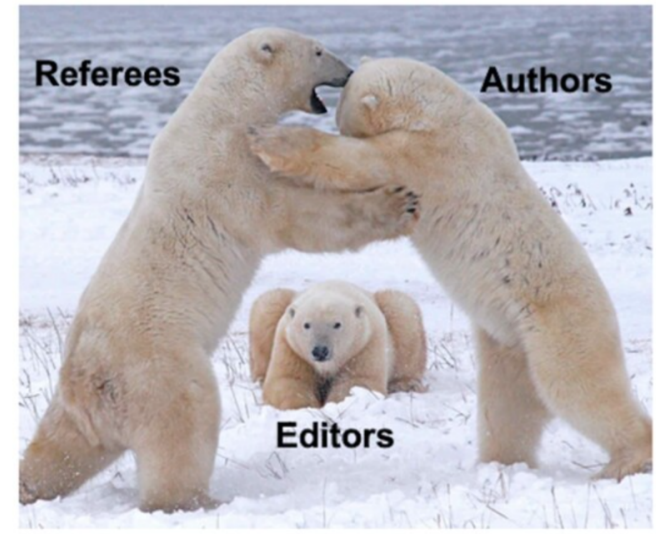

Source: Getty image. Idea: Xu Zhang, CAS - ION

\section{WILEY}

Figure 1: It may look this way sometimes, but this is NOT how the peer-review process works 